\title{
Design, Synthesis and Characterization of Bitumen Emulsifiers Based on Molecular Simulation
}

\author{
X.-J. Kong, J.-L. Wang, Z.-P. Liang, L.-J. Zhang, and J.-H. Zhao \\ School of Chemistry \& Chemical Engineering and Environmental Engineering, Weifang University, \\ Weifang 261061 , P. R. China
}

\begin{abstract}
Under the guidance of molecular simulation technology, the Monte Carlo molecular mechanics simulation was used to calculate the compatibility of different lipophilic groups with each component of bitumen, and the compatibility of different hydrophilic groups with water. Based on the calculated results of interaction parameters Chi and mixture energy $E_{\text {mix }}$ the preferred structures of lipophilic and hydrophilic groups of bitumen emulsifier were determined. The target bitumen emulsifier was then synthesized by the reaction of organic acid and polyamine. The molecular simulation results showed that the compatibility of lipophilic group $\mathrm{T}_{11}$ with the bitumen was the best, and the mixing ability of the hydrophilic group $\mathrm{H}_{5}$ with water was excellent. The experimental results show that the preferred structures $\mathrm{T}_{11} \mathrm{H}_{5}$ had a good emulsifying performance to prepare emulsified bitumen with good storage stability, consistent with the results of the molecular simulation.
\end{abstract}

\section{Keywords}

Molecular simulation, bitumen, emulsifier, emulsified bitumen

\section{Introduction}

Emulsified bitumen technology is one of the most economical and effective ways to repair road rut and many other road distresses. It can be used as a preventive maintenance technology or directly applied to the surface wear layer of new roads. ${ }^{1-3}$ As a kind of surfactant, bitumen emulsifier is the core of the emulsified bitumen technology, ${ }^{4}$ which will directly affect construction quality and progress. ${ }^{5}$ At present, there are still many deficiencies in the research of bitumen emulsifier. Firstly, the theoretical design of emulsifier lacks theoretical guidance. The research on bitumen emulsifier and formula is often based on experience, relying on a large number of emulsification experiments. Secondly, most of the research on emulsified bitumen lacks the micro-mechanism of the interaction between the emulsifier structure and the bitumen component. Research on these two aspects is seldom reported, which is of very important theoretical and practical significance for the design of emulsifier structure and emulsified bitumen system.

Molecular simulation technology provides strong technical support for the above research. It is an emerging computational chemistry based on computer science and theoretical chemistry. With its powerful computational ability and image display ability, molecular simulation simulates the structure and behaviour of molecules at molecular level to help researchers understand the basic characteristics of the research object from the microscopic point of view. In recent years, it has been widely used in many fields, such as molecular design and mechanism research of corrosion inhibitors; ${ }^{6-8}$ the study of the solvent effect in the reaction system using quantum mechanics, molecular

${ }^{*}$ Corresponding author: Xiangjun Kong, Ph. D

email: kongxiangjun1982@163.com mechanics, and Monte Carlo simulations, ${ }^{9}$ and molecular dynamics simulation of the adsorption behaviour at the gas-liquid interface. ${ }^{10-12}$ The information obtained by molecular simulation can not only explain the experimental results, but also predict the experimental results and provide technical support for the design and development of new materials.

In this paper, the molecular structure of emulsifier was first designed by molecular simulation method to determine the preferred lipophilic and hydrophilic structure. Based on this, the designed emulsifier was synthesized by the reaction of organic acid and polyamine, and its surface activity and emulsification property were measured.

\section{Experimental and simulation methods}

\subsection{Materials}

Tetraethylenepentamine, lauric acid, hydrochloric acid, xylene, anhydrous ethanol were analytically pure and produced by Sinopharm Chemical Reagent Co., Ltd.

\subsection{Molecular simulation method}

For good emulsifying performance, the lipophilic group of bitumen emulsifier should have a suitable chain length, in order to have good compatibility with the bitumen. On the other hand, the hydrophilic group should have a good match with the lipophilic group to reach the appropriate hydrophilic-lipophilic balance (HLB) value. In this paper, the chemical structure of imidazoline-type bitumen emulsifier with different lipophilic and hydrophilic group is shown in Fig. 1. Authors selected the carbon chain length 
of $\mathrm{C}_{8}$ to $\mathrm{C}_{18}$ as lipophilic group, and imidazoline derivatives with different branches of polyene polyamine as hydrophilic group. For convenience, the emulsifier molecules are represented as $\mathrm{T}_{n} \mathrm{H}_{\mathrm{m}}$, where $n$ is the carbon number of a long-chain lipophilic group, and $m$ represents the number of $\mathrm{N}$ atoms in a hydrophilic group.

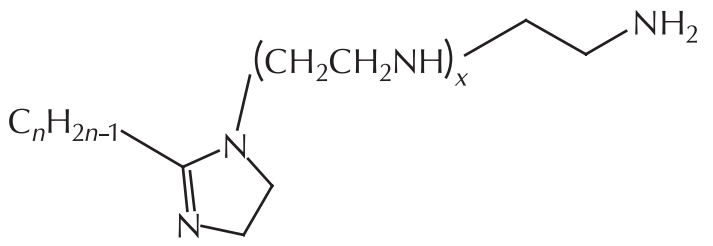

Fig. 1 - Chemical structure of imidazolines $n=9,11,13,15,17$; $x=0,1,2$

The physical and chemical properties of $\mathrm{AH}-70$ bitumen, including the four components of bitumen, elemental composition, hydrogen spectrum, molecular weight, etc., were analysed to gain the structural parameters and build the average molecular structure of bitumen components; The Monte Carlo molecular mechanics simulation was used to calculate the compatibility of different lipophilic groups with each component of bitumen and the compatibility of different hydrophilic groups with water. The preferred structures of lipophilic and hydrophilic groups of bitumen emulsifier were determined according to the calculated results.

The specific simulation method was as follows: firstly, the molecular structure model of the water, emulsifier, and the four components of bitumen were built by using Visualizer module of the calculation software Materials Studio 6.0. These molecular structures were then geometrically optimized using Forcite module. The Compass force field was used in the optimization process. Finally, the Blends module was used to calculate the interaction parameters Chi and the mixing energy $E_{\text {mix }}$ at the simulation temperature of $298 \mathrm{~K}$.

\subsection{Experimental method}

\subsubsection{Characterization analysis of bitumen chemical structure}

Elemental analysers of Elemental Analy Sensysteme $\mathrm{GmbH}$ Vario Elc III were used to quantitatively analyse the content of $\mathrm{C}, \mathrm{H}, \mathrm{N}, \mathrm{S}$ and other elements of bitumen by combustion chromatography. Infrared analysis was performed using a US NEXUS Fourier Transform Infrared Spectrometer (FT-IR). The sample treatment method was a coating method. The ${ }^{1} \mathrm{H}-\mathrm{NMR}$ measurement was performed on an AV-500 superconducting nuclear magnetic resonance spectrometer. The solvent was $\mathrm{CDCl}_{3}$, and tetramethylsilane (TMS) was used as the internal standard, and the scan width was $10000 \mathrm{~Hz}$. The KNAUER K-7000 vapour pressure permeameter was used to determine the average molecular mass at $45{ }^{\circ} \mathrm{C}$ with benzene as the solvent.

\subsubsection{Synthesis of emulsifier}

After the molecular simulation design, organic acids and organic amines with the best calculation results were taken as raw materials. Organic acids and organic polyamines with the molar ratio of $1: 1.1$, and a certain amount of xylene are added into the reactor. The reactor was filled with $\mathrm{N}_{2}$ and heated to reflux with stirring and an amidation reaction occurred at $140{ }^{\circ} \mathrm{C}$. After the amount of water reached the theoretical value, the xylene was distilled off and the vacuum degree of the reactor was controlled at $0.096 \mathrm{MPa}$. The temperature was then raised to $240{ }^{\circ} \mathrm{C}$ and the cyclization reaction was carried out for $4 \mathrm{~h}$ to obtain a target product.

\subsubsection{Emulsified bitumen preparation}

Firstly, a concentration of 400 g aqueous emulsifier solution was prepared, the $\mathrm{pH}$ value of which was adjusted to 2.0 and heated to $40-60{ }^{\circ} \mathrm{C}$. An amount of $600 \mathrm{~g}$ of bitumen was then weighed and heated to $135^{\circ} \mathrm{C}$. The emulsifier aqueous solution was poured into colloid mill, followed by slowly pouring in the the bitumen for shearing and emulsification for about $1 \mathrm{~min}$ to obtain an emulsified bitumen.

\subsubsection{Emulsified bitumen performance test}

Referring to the Technical Specifications for BCR Emulsified Bitumen in the "Test Procedures for Bitumen and Bitumen Mixtures for Highway Engineering" (JTJ 052--2000) issued by the Ministry of Transport of the People's Republic of China, the storage stability was tested as the main index of the emulsified bitumen performance.

\section{Results and discussion}

\subsection{Chemical structure of the bitumen}

From solubility point of view, a four-components concept was proposed by the American Society for Testing and Materials (ASTM) D4124-09, in which bitumen is divided into saturate, aromatics, resins, and asphaltenes, abbreviated as SARA. ${ }^{13}$ The physicochemical properties of the $\mathrm{AH}-70$ bitumen were analysed, including the fractions, elemental composition, hydrogen spectrum, and molecular mass $M$ of the SARA. The structural parameters of the bitumen component were analysed, and the average molecular structure of the SARA was constructed. The physical and chemical properties of the $\mathrm{AH}-70$ bitumen are shown in Tables 1 to 3.

Table 1 - Component fractions and relative molecular mass of $\mathrm{AH}-70$ bitumen

\begin{tabular}{c|c|c}
\hline Bitumen components & Mass fraction $/ \%$ & $\mathrm{M} / \mathrm{g} \mathrm{mol}^{-1}$ \\
\hline saturate & 27.37 & 707.31 \\
aromatics & 32.80 & 755.27 \\
resins & 39.16 & 828.56 \\
asphaltenes & 0.67 & 2216.07 \\
\hline
\end{tabular}


Table 2 - Elemental composition of the bitumen components

\begin{tabular}{c|c|c|c|c|c}
\hline $\begin{array}{c}\text { Bitumen } \\
\text { components }\end{array}$ & $w(\mathrm{C}) / \%$ & $w(\mathrm{H}) / \%$ & $w(\mathrm{~N}) / \%$ & $w(\mathrm{~S}) / \%$ & $w(\mathrm{O}) / \%{ }^{*}$ \\
\hline saturate & 87.27 & 12.73 & - & - & - \\
aromatics & 86.58 & 11.87 & 0.63 & 0.48 & 0.46 \\
resins & 85.51 & 11.14 & 1.73 & 0.80 & 0.83 \\
asphaltenes & 77.49 & 10.06 & 1.19 & 2.00 & 9.26 \\
\hline
\end{tabular}

* Oxygen content obtained by the subtractive method.

Table 3 - Hydrogen spectrum of the SARA

\begin{tabular}{c|c|c|c|c}
\hline $\begin{array}{c}\text { Bitumen } \\
\text { components }\end{array}$ & $\mathrm{H}_{\mathrm{A}}$ & $\mathrm{H}_{\alpha}$ & $\mathrm{H}_{\beta}$ & $\mathrm{H}_{\gamma}$ \\
\hline saturate & 0.0029 & 0.0215 & 0.6238 & 0.3517 \\
aromatics & 0.0670 & 0.1192 & 0.5609 & 0.2529 \\
resins & 0.0457 & 0.1577 & 0.5938 & 0.2034 \\
asphaltenes & 0.0377 & 0.1573 & 0.6112 & 0.1944 \\
\hline
\end{tabular}

where, $\mathrm{H}_{\mathrm{A}}$ is the fraction of hydrogen attached to the aromatic carbon. $\mathrm{H}_{\alpha}$ is the fraction of hydrogen attached to the alpha carbon of the aromatic ring. $\mathrm{H}_{\beta}$ is the fraction of hydrogen on the beta carbon of the aromatic ring and hydrogen of $\mathrm{CH}_{2}$ and $\mathrm{CH}$ farther than $\beta . \mathrm{H}_{\gamma}$ is the fraction of hydrogen attached to the $\gamma$-position carbon of the aromatic ring and the fraction of hydrogen on the $\mathrm{CH}_{3}$ group farther than $\gamma$.

Based on the elemental composition, average relative molecular mass and ${ }^{1} \mathrm{H}-\mathrm{NMR}$ information, the average structural parameters of the bitumen components were calculated using the modified B-L method, ${ }^{14}$ as shown in Table 4.

Table 4 - Structural parameters of the SARA

\begin{tabular}{c|c|c|c|c|c|c|c}
\hline $\begin{array}{c}\text { Bitumen } \\
\text { components }\end{array}$ & $f_{\mathrm{A}}$ & $f_{\mathrm{N}}$ & $f_{\mathrm{p}}$ & $R_{\mathrm{T}}$ & $R_{\mathrm{A}}$ & $R_{\mathrm{N}}$ & $L$ \\
\hline saturate & - & 0.30 & 0.70 & - & - & 5.13 & - \\
aromatics & 0.30 & 0.24 & 0.46 & 6.98 & 3.63 & 3.36 & 3.95 \\
resins & 0.30 & 0.13 & 0.57 & 7.54 & 4.97 & 2.57 & 5.65 \\
asphaltenes & 0.47 & 0.27 & 0.32 & 34.37 & 23.75 & 11.22 & 3.46 \\
\hline
\end{tabular}

where, $f_{\mathrm{A}}, f_{\mathrm{N}}$ and $f_{\mathrm{p}}$ are the aromatic carbon fraction, the cycloalkane carbon fraction and the alkane carbon fraction, respectively. $R_{\mathrm{T}}, R_{\mathrm{A}}, R_{\mathrm{N}}$ and $L$ are the total number of rings, the number of aromatic rings, the number of cycloalkanes, and the number of alkyl chain substitutions, respectively.

Based on the structural parameters above, the average molecular structure of the SARA was constructed, as shown in Fig. 2.
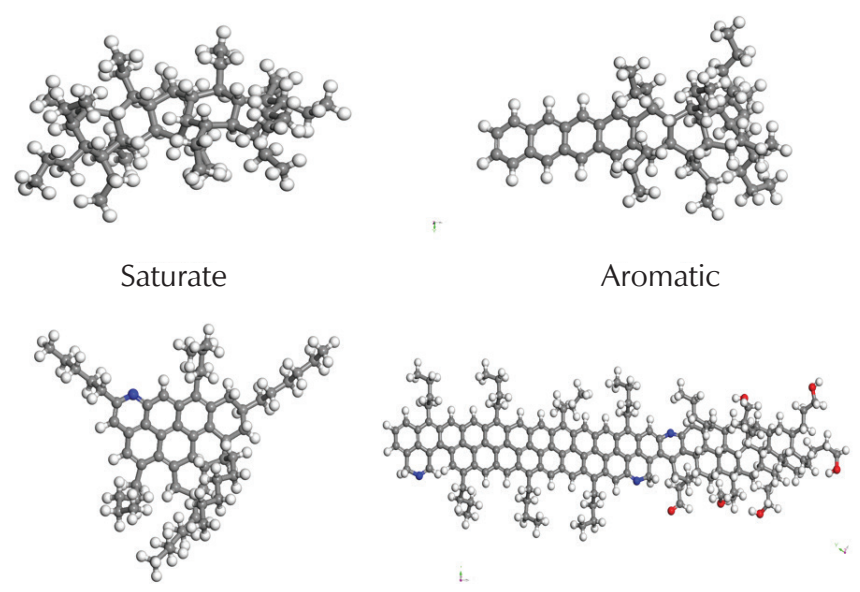

Resin

Asphaltene

Fig. 2 - Molecular structures of the SARA

\subsection{Molecular simulation results}

The Monte Carlo method was used to study the interactions between the lipophilic groups with different carbon chain length and the four component model compounds of bitumen at $293 \mathrm{~K}$. The results are shown in Figs. 3 to 6. Among them, the abscissa " $n$ " represents the carbon number of the lipophilic group, and the ordinates $E_{\text {mix }}$ and Chi are the mixing energy and interaction parameters between the two components, respectively. The larger the value is, the worse the compatibility and the stronger the repulsion between the two components.

As can be seen from Figs. 3-6, the interaction between the lipophilic groups with different chain lengths and saturate and aromatics in the bitumen shows a uniform interaction law. That is, with the increase in the lipophilic chain length, $E_{\text {mix }}$ and the interaction parameter Chi between the bitumen components (the saturated and aromatic components) and lipophilic groups showed a trend of decreasing first and then increasing. Among them, $E_{\text {mix }}$ and interaction parameters between $\mathrm{C}_{11}$ and the bitumen saturated component and aromatic component were the smallest, indicating its compatibility with the bitumen was the best. There was no obvious regularity in the interaction between the lipophilic groups with different chain lengths and the resin and asphaltenes. Taking into account the colloidal structure of bitumen, which was described as a colloidal dispersion of asphaltenes micelles in the maltenes, and the resins as the polar components of the maltenes to stabilize the asphaltene micelles, the lipophilic group of the emulsifiers should have better compatibility with the saturated and aromatic components, i.e., the maltenes. In summary, the preferred emulsifier lipophilic carbon chain length is $\mathrm{C}_{11}$.

The influence of the hydrophilic group structure on the $E_{\text {mix }}$ and Chi between the hydrophilic groups of the emulsifier and the water was investigated. The result is shown in Fig. 7. 


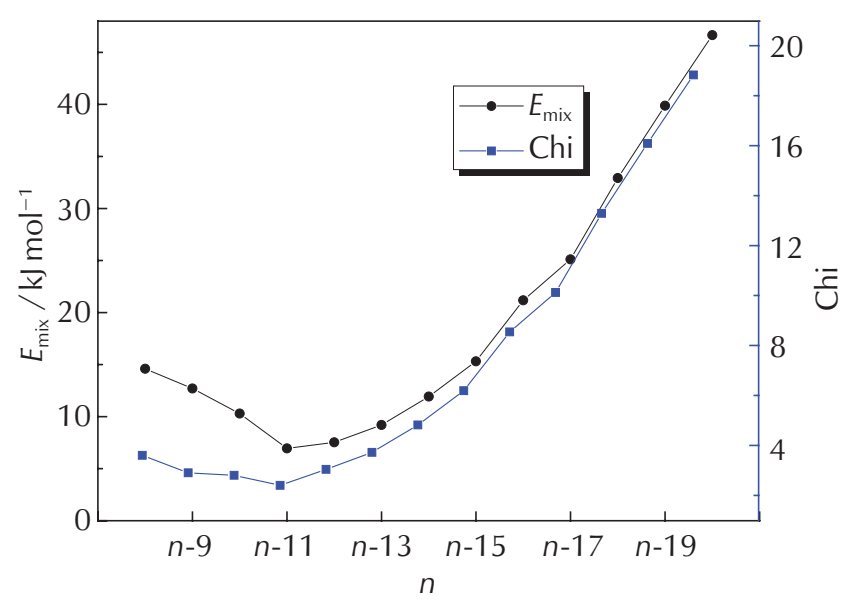

Fig. 3 - Interactions between the lipophilic groups and the saturate

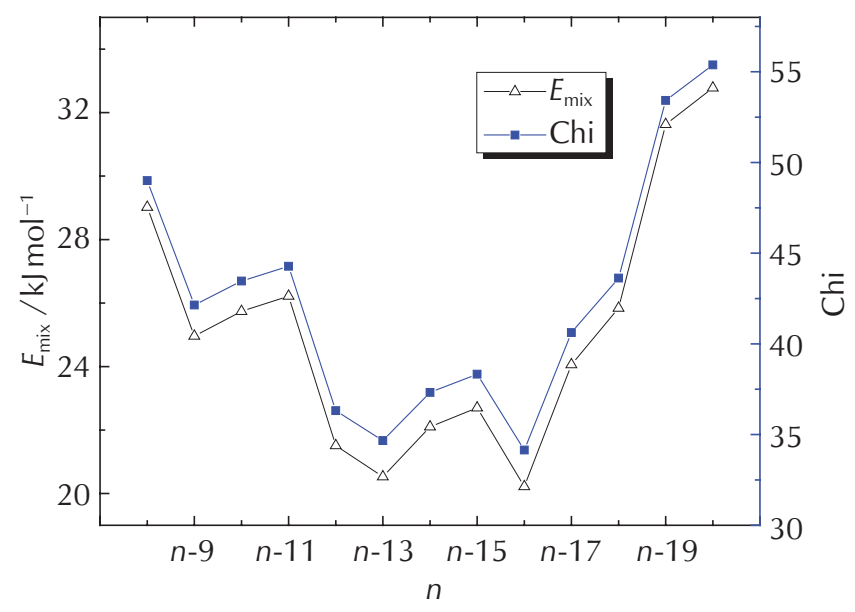

Fig. 5 - Interactions between the lipophilic groups and the resins

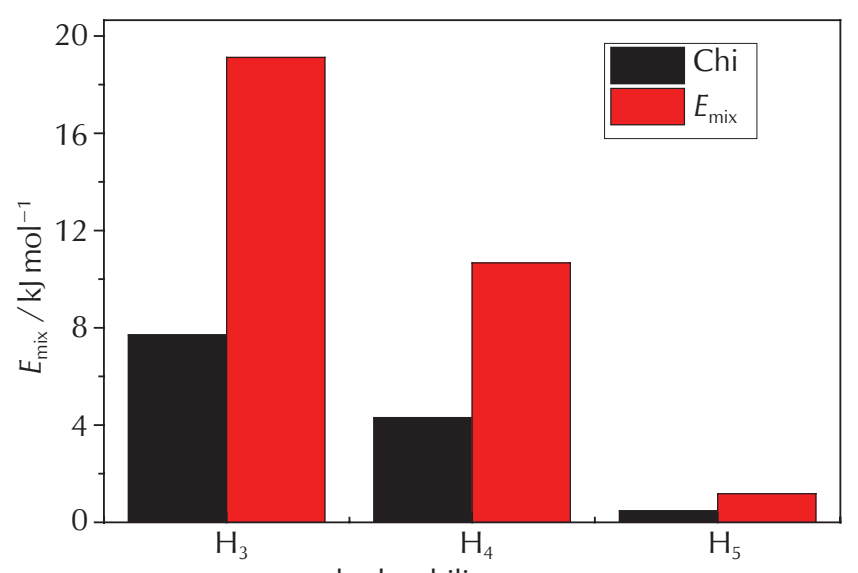

hydrophilic structure

Fig. 7 - Interactions between the hydrophilic groups of emulsifier and water

It can be seen from Fig. 7 that different hydrophilic base structures have a great influence on the interaction of emulsifiers with water. With the increase in the number

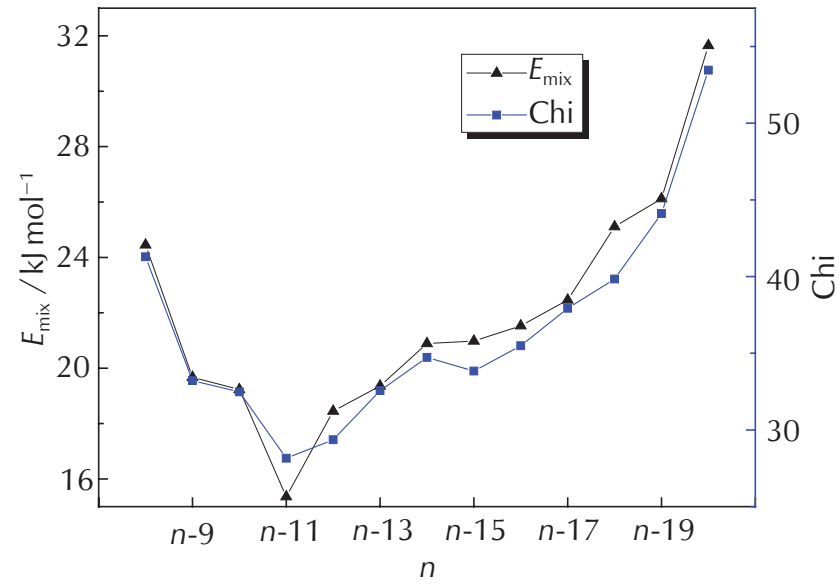

Fig. 4 - Interactions between the lipophilic groups and the aromatics

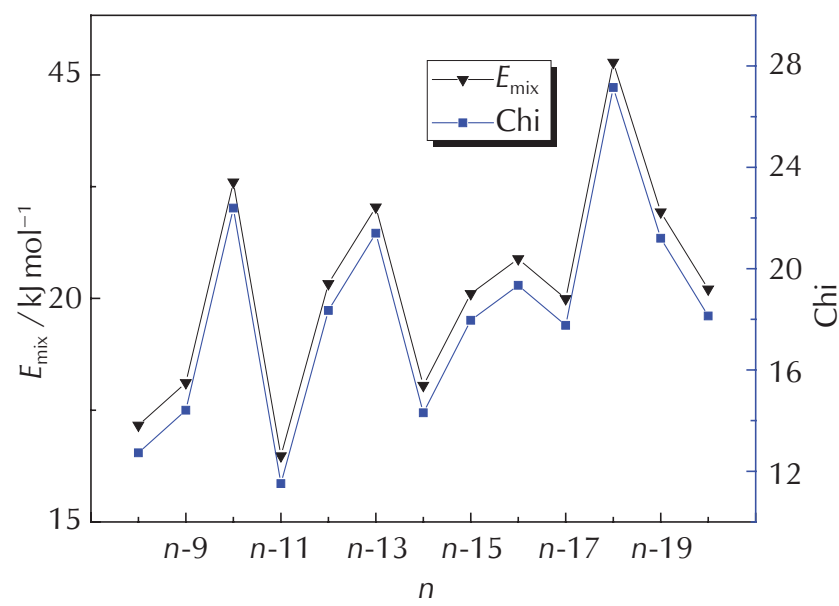

Fig. 6 - Interactions between the lipophilic groups and the asphaltenes

of nitrogen atoms, the compatibility of hydrophilic groups with water improved, and the interaction parameters and the mixing energy reduced. The mixing ability of the hydrophilic group produced with tetraethylene pentamine as a raw material and water was very small, $1.18 \mathrm{~kJ} \mathrm{~mol}^{-1}$, and its hydrophilicity was excellent.

Based on the results of the above simulation, it is considered that the imidazoline hydrophilic group formed by a lipophilic group having a chain length of about $\mathrm{C}_{11}$ and tetraethylene pentamine is a structure of a suitable synthetic bitumen emulsifier. Subsequently, bitumen emulsifiers with different chain length lipophilic groups and different hydrophilicity structures were synthesized in the laboratory. The results obtained by molecular simulation were verified by evaluating the surface activity of the emulsifier and the emulsifying properties of the bitumen. The raw material acids mainly include organic monocarboxylic acids of different carbon chain lengths $\left(C_{9}\right.$ to $\left.C_{17}\right)$. The raw material amines mainly include diethylenetriamine, triethylenetetramine, and tetraethylenepentamine. The above materials were used to synthesize bitumen emulsifiers. The performance was investigated and compared with the results of the molecular simulation. 


\subsection{Performance of different structural bitumen emulsifiers}

The bitumen emulsifiers with different lipophilic and hydrophilic groups were synthesized by the synthesis method described in section 2.3.2. The structural characterization of these different structural emulsifiers was studied in our previously published article, ${ }^{15}$ and will not be described here. We used these products as emulsifiers to prepare emulsified bitumen. The emulsification process conditions are shown in Table 5.

Table 5 - Emulsification process conditions

\begin{tabular}{l|c}
\hline Item & Condition \\
\hline mass fraction of bitumen $/ \%$ & 60 \\
mass fraction of emulsifier $/ \%$ & 1.5 \\
bitumen temperature $/{ }^{\circ} \mathrm{C}$ & 135 \\
emulsifier solution temperature $/{ }^{\circ} \mathrm{C}$ & 50 \\
$\mathrm{pH}$ value of emulsifier solution & 2.0 \\
\hline
\end{tabular}

The 1-day and 5-day stability of the prepared emulsified bitumen were measured to examine the effect of different structural emulsifiers on the stability of the emulsified bitumen. The results are shown in Table 6.

Table 6 - Emulsification performance test results

\begin{tabular}{c|c|c}
\hline \multirow{2}{*}{ Emulsifier } & \multicolumn{2}{|c}{ Storage stability } \\
\cline { 2 - 3 } & $1 \mathrm{~d} / \%$ & $5 \mathrm{~d} / \%$ \\
\hline $\mathrm{T}_{9} \mathrm{H}_{3}$ & 2.47 & 6.78 \\
$\mathrm{~T}_{9} \mathrm{H}_{4}$ & 1.87 & 7.52 \\
$\mathrm{~T}_{9} \mathrm{H}_{5}$ & 0.99 & 10.47 \\
$\mathrm{~T}_{11} \mathrm{H}_{3}$ & 1.58 & 6.13 \\
$\mathrm{~T}_{11} \mathrm{H}_{4}$ & 2.04 & 6.47 \\
$\mathrm{~T}_{11} \mathrm{H}_{5}$ & 0.18 & 0.84 \\
$\mathrm{~T}_{13} \mathrm{H}_{3}$ & 1.26 & 6.97 \\
$\mathrm{~T}_{13} \mathrm{H}_{4}$ & 1.58 & 7.87 \\
$\mathrm{~T}_{13} \mathrm{H}_{5}$ & 1.08 & 7.73 \\
$\mathrm{~T}_{15} \mathrm{H}_{3}$ & 0.22 & 6.36 \\
$\mathrm{~T}_{15} \mathrm{H}_{4}$ & 2.37 & 7.35 \\
$\mathrm{~T}_{15} \mathrm{H}_{5}$ & 0.15 & 5.65 \\
$\mathrm{~T}_{17} \mathrm{H}_{3}$ & 2.99 & 5.87 \\
$\mathrm{~T}_{17} \mathrm{H}_{4}$ & 3.54 & 8.48 \\
$\mathrm{~T}_{17} \mathrm{H}_{5}$ & 2.26 & 11.25 \\
\hline
\end{tabular}

It can be seen from Table 6 that emulsified bitumen produced by emulsifier $\mathrm{T}_{11} \mathrm{H}_{5}$ had excellent storage stability for $1 \mathrm{~d}$ and $5 \mathrm{~d}$, good compatibility with bitumen, no fractionation phenomenon, and emulsified bitumen stability, and surface activity of emulsifier for reducing surface tension. There is a certain correlation relationship. Generally speaking, an emulsifier capable of effectively reducing the surface tension, and the prepared emulsified bitumen have relatively good storage stability. Finally, the storage stability of the emulsified bitumen was used as the evaluation index to determine that the emulsifier was $\mathrm{T}_{11} \mathrm{H}_{5}$, which was also consistent with the results of the molecular simulation.

\section{Conclusion}

The lipophilic groups with different chain lengths exhibited the same interaction rules as the saturated and aromatic components in the bitumen. As the chain length of the lipophilic group increases, $E_{\text {mix }}$ and the interaction parameter Chi between the lipophilic group and the saturated and aromatic components firstly decrease and then increase. $\mathrm{C}_{11}$ is a suitable lipophilic structure. The structure of the hydrophilic group has a great influence on the interaction of the emulsifier with water. With the increase in the nitrogen-containing groups in the hydrophilic group, the compatibility of the hydrophilic group with water improves, and the interaction parameters and mixing energy decrease. The hydrophilicity of the hydrophilic group generated with tetraethylene pentamine as a raw material and water is minimized, and the hydrophilic property is excellent.

The emulsifier structure, $\mathrm{T}_{11} \mathrm{H}_{5}$, which was optimized by molecular simulation, has good emulsification performance. Emulsified bitumen prepared with bitumen emulsifier $\mathrm{T}_{11} \mathrm{H}_{5}$ has good storage stability. Molecular simulation technology can provide strong guidance for the structure design of bitumen emulsifier.

\section{ACKNOWLEDGEMENTS}

This work was sponsored by the Weifang University Doctoral Research Fund (2018BS08) and Weifang Science \& Development Plan (2018GX019).

\section{List of abbreviations and symbols}

$\begin{array}{ll}E_{\mathrm{mix}} & \text { - the mixing energy } \\ \text { HLB } & \text { - hydrophilic-lipophilic balance value } \\ \text { TMS } & \text { - tetramethylsilane } \\ \text { SARA } & \text { - saturate, aromatics, resins and asphaltenes } \\ M & \text { - relative molecular mass } \\ f_{\mathrm{A}} & \text { - aromatic carbon fraction } \\ f_{\mathrm{N}} & \text { - cycloalkane carbon fraction } \\ f_{\mathrm{p}} & \text { - alkane carbon fraction } \\ R_{\mathrm{T}} & \text { - total number of rings } \\ R_{\mathrm{A}} & \quad \text { - number of aromatic rings } \\ R_{\mathrm{N}} & \quad-\text { number of cycloalkanes } \\ L & \quad-\text { number of alkyl chain substitutions }\end{array}$




\section{References}

\section{Literatura}

1. D. M. Pittenger, D. D. Gransberg, M. Zaman, C. Riemeer, Comparative Analysis of Microsurfacing and Portland Cement Slurry Seal for Rut Filling, Transportation Research Board 93 $3^{\text {rd }}$ Annual Meeting, 2014.

2. T. Erwin, S. L. Tighe, Safety effect of preventive maintenance: a case study of microsurfacing, Transp. Res. Rec. 2044 (2008) 79-85, doi: https://doi.org/10.3141/2044-09.

3. Micro-surfacing: Guidelines for Use and Quality Assurance, International Slurry Surfacing Association, 1998.

4. J. Kennedy, Alternative Materials and Techniques for Road Pavement Construction, London: DOE Energy Efficiency Office, 1997.

5. M. Miljković, M. Radenberg, Characterising the influence of bitumen emulsion on asphalt mixture performance, Mater. Struct. 48 (2015) 2195-2210, doi: https://doi.org/10.1617/ s11527-014-0302-y.

6. Y. Yan, X. Wang, Y. Zhang, P. Wang, X. Cao, J. Zhang, Molecular dynamics simulation of corrosive species diffusion in imidazoline inhibitor films with different alkyl chain length, Corrosion Sci. 73 (2013) 123-129, doi: https://doi.org/10.1016/j. corsci.2013.03.031.

7. J. Liu, W. Yu, J. Zhang, S. Hu, L. You, G.Qiao, Molecular modeling study on inhibition performance of imidazolines for mild steel in $\mathrm{CO}_{2}$ corrosion, Appl. Surf. Sci. 256 (2010) 4729 4733, doi: https://doi.org/10.1016/j.apsusc.2010.02.082.

8. D. Gao, Y. K. Pan, A QM/MM Monte Carlo simulation study of solvent effects on the decarboxylation reaction of $\mathrm{N}$-carboxy-2-imidazolidinone anion in aqueous solution, J. Org. Chem. 64 (1999) 1151-1159, doi: https://doi.org/10.1021/ jo981523g.
9. H. Hu, L. Du, X. Li, H. Zhao, X. Zhang, S. Shi, H. Li, X. Tang, J. Yang, Experimental, Quantum Chemical and Molecular Dynamics Studies of Imidazoline Molecules Against the Corrosion of Steel and Quantitative Structure- Activity Relationship Analysis Using the Support Vector Machine (SVM) Method, Int. J. Electrochem. Sci. 8 (2013) 11228-11247, url: http:// www.electrochemsci.org/papers/vol8/80911228.pdf.

10. L. Wang, R. Liu, Y. Hu, W. Sun, Adsorption of mixed DDA/ $\mathrm{NaOL}$ surfactants at the air/water interface by molecular dynamics simulations, Chem. Eng. Sci. 155 (2016) 167-174, doi: https://doi.org/10.1016/j.ces.2016.08.012.

11. C. Wang, Y. Tan, Z. Jiang, X. Lin, S. Hu, Molecular structure of ionic surfactant solution surface and effects of counter-ion therein - a joint investigation by simulation and experiment, Colloid Polym. Sci. 293 (2015) 3479-3486, doi: https://doi. org/10.1007/s00396-015-3685-6.

12. A. J. Borysik, Structure and Dynamics of a Protein-Surfactant Assembly Studied by Ion-Mobility Mass Spectrometry and Molecular Dynamics Simulations, Anal. Chem. 87 (2015) 8970-8976, doi: https://doi.org/10.1021/acs.analchem.5b02172.

13. D. Lesueur, The colloidal structure of bitumen: consequences on the rheology and on the mechanisms of bitumen modification, Adv. Colloid Interface Sci. 145 (2009) 42, doi: https://doi.org/10.1016/j.cis.2008.08.011.

14. J. Christopher, A. S.Sarpal, G. S. Kapur, A. Krishna, B. R.Tyagi, M. C. Jain, S. K.Jain, A. K. Bhatnagar, Chemical structure of bitumen-derived asphaltenes by nuclear magnetic resonance spectroscopy and X-ray diffractometry, Fuel 75 (1996) 9991008, doi: https://doi.org/10.1016/0016-2361(96)00023-3.

15. X. Kong, C. Qian, W. Fan, Z. Liang, Experimental and QSAR study on the surface activities of alkyl imidazoline surfactants, J. Mol. Struct. 1156 (2018) 164-171, doi: https:// doi.org/10.1016/j.molstruc.2017.11.102.

\section{SAŽETAK \\ Dizajn, sinteza i karakterizacija emulgatora za bitumen dobivenoga molekularnom simulacijom \\ Xiangjun Kong, Jinlan Wang, Zupei Liang, Lijun Zhang i Junhe Zhao}

Za izračun kompatibilnosti različitih lipofilnih skupina sa svakom komponentom bitumena i kompatibilnosti različitih hidrofilnih skupina s vodom primijenjena je Monte Carlo simulacija molekularne mehanike. Na temelju izračunatih parametara interakcije Chi i energije miješanja $E_{\text {mix }}$ određene su preferirane lipofilne i hidrofilne skupine emulgatora za bitumen. Zeljeni emulgator za bitumen sintetiziran je reakcijom organske kiseline i poliamina. Rezultati molekularne simulacije pokazali su da najbolju kompatibilnost s bitumenom ima lipofilna skupina $T_{11}$, a da hidrofilna skupina $\mathrm{H}_{5}$ ima odličnu mješljivost s vodom. Prema eksperimentalnim rezultatima, preferirana struktura $\mathrm{T}_{11} \mathrm{H}_{5}$ ima dobra svojstva emulgiranja za pripremu bitumena, a emulzija ostaje stabilna pri skladištenju što je u skladu s rezultatima molekularne simulacije.

Ključne riječi

Molekularna simulacija, bitumen, emulgator, emulgirani bitumen

School of Chemistry \& Chemical Engineering

and Environmental Engineering, Weifang

University, Weifang 261 061, Kina
Izvorni znanstveni rad Prispjelo 15. travnja 2018. Prihvaćeno 14. lipnja 2018. 